\title{
Willing to pay more for high-quality schools?
}

A hedonic pricing and propensity score matching approach

\author{
Linchuan Yang ${ }^{1}$, Bo Wang ${ }^{2 *}$, Yunyi Zhang ${ }^{3}$, Ziwei Ye ${ }^{4}$, Yuzhuo Wang ${ }^{5}$, \\ Pengfei $\mathrm{Li}^{6}$
}

1 Faculty of Architecture, the University of Hong Kong

2 Department of Geography, the University of Hong Kong

3 Shanghai Digital Intelligence System Technology Co.Ltd

4 Taubman College of Architecture and Urban Planning, University of Michigan

5 China Academy of Urban Planning and Design

6 School of Architecture and Civil Engineering, Xiamen University, Xiamen

* Corresponding Author, Email: wangbo.nju@gmail.com

Received: June 11, 2016; Accepted: June 23, 2017

Keywords: Box-Cox transformation; Hedonic price model, School attendance zone Property price, Propensity score matching, Xuequfang

\begin{abstract}
Principally, the enrolment of elementary school in China is solely based on residential location. Due to the scarcity of prestigious schools, the household registration (or hukou in Chinese) and the territorial-based school admission policy, a feasible approach for parents to provide the children with good education is to purchase the house in the attendance zone of a high-quality school (or xuequfang in Chinese). The supply-demand imbalance gives rise to the xuequfang phenomenon (much higher prices of xuequfang relative to nonxuequfang). Based on 1250 housing samples in 286 multi- or high-storey residential districts, this paper firstly develops two basic and four Box-Cox transformed hedonic price models to estimate the effect of high-quality schools on residential property prices. The consistency of six models greatly enhances the credibility of this study. Moreover, complementary, the propensity score matching technique is used to estimate the treatment effect. The two methods consistently suggest that residential property values are affected by top-tier schools. They reveal that xuequfang exhibit values that are between $9.3 \%$ and $12.1 \%$ higher than non-xuequfang, ceteris paribus. The negative influences of the xuequfang phenomenon and several countermeasures (gradually reforming household registration system, optimizing resource distribution to balance the quality of education, highlighting family education and children's all-round development) are discussed.
\end{abstract}

\section{INTRODUCTION}

Education, work and retirement, are three stages of our life. Education is the foundation of a nation and is closely related to the overall quality of citizens as well as the long-term development of a nation. The importance of education to individuals and a state has been universally recognized.

"Residential property is a multidimensional commodity, characterized by durability and structural inflexibility as well as spatial fixity" ((So, Tse, \& Ganesan, 1997), p.40). It is distinguished by a number of characteristics 
(e.g., size, age, transport accessibility), some of which would influence its price. Understandably, high-quality educational resources are unevenly distributed due to scarcity. They would, in theory, affect residential property prices positively. A number of parents tend to live in the properties near attractive schools for access to high-quality education. As a result, they are willing to pay higher prices for those dwelling units, a portion of which are parents' investment in their children's future.

\subsection{School and housing prices in the Western context}

School quality has been long perceived as a crucial determinant of residential property prices. The externality of prestigious schools has been found to be capitalized in housing prices (Black, 1999; Clapp, Nanda, \& Ross, 2008).

How to identify high-quality schools? Western researchers have introduced a number of judging criteria, such as educational outcomes (test scores or pass rates), school expenditure, earning as well as student-teacher ratio.

There is a wide range of previous literature concerned with the capitalization benefits of leading schools in the Western context. Hayes and Taylor (1996) validated a common wisdom: neighborhood school was an important locational attribute associated with residential property price. Black (1999) pointed out that the estimation without sufficiently controlling for neighborhood attributes would overstate the influence of prestigious schools because better schools tended to be located in better neighborhoods. For this reason, he proposed a novel approach (i.e., boundary fixed effect method), compared the prices of properties located on opposite sides of attendance district geographic boundaries, and confirmed parents' willingness-to-pay for prestigious schools. Sedgley, Williams, and Derrick (2008) presented consistent and strong evidence of the capitalization of test scores and demonstrated that properties within good school attendance zones were more expensive than those not situated in these areas. Using panel data of housing transactions in the state of Connecticut spanning eleven years, Clapp, Nanda, and Ross (2008) ascertained the relationship between property values and school attendance zone attributes and supported Black (1999)'s argument that failing to control for unobservable components of neighborhood quality would result in an overestimation of the test score's effect on residential property values.

\subsection{School and housing prices in the Chinese context}

In China, the entrenched traditional thought of "expectations for their children (or wangzichenglong in Chinese)" places education on a more important position in the mindsets of most of the parents. That is, both historically and currently, people have a particular interest in investing in the children's (even grandchildren's) education which is thought to help retain social capital ( $\mathrm{Wu}, \mathrm{Q}$. et al., 2014). Due to fairly fierce social competition, education has become an important means to enhance competitiveness and pursue social capital, which eventually enhances career prospects.

Principally, the admission policy of public elementary school is territorial-based, meaning that a school enrolls school-age children based on school attendance zone. In other words, in most cases, restricted by household registration (or hukou in Chinese), only the children of the owners 
(rather than the tenants) of properties located in the attendance zone of school A are entitled to be enrolled in school A. A child's elementary school is determined by the location of parents' hukou (Wu, Q., Zhang, \& Waley, 2016). Fettered by this, school-age children cannot freely attend primary schools in accordance with their parents' willingness. Today, family investment in education shows a very distinctive feature, that is, buying a residential property in the attendance zone of a prestigious school. In order to offer their children the access to high-quality schools, parents strive to pay higher prices to purchase a xuequfang. Purchasing a xuequfang becomes the most common approach for better education. The xuequfang phenomenon, which refers to much higher prices of xuequfang relative to non-xuequfang, has become a focus of the society. In this study, the xuequfang phenomenon refers to the economic aspect of jiaoyufication, a new form of gentrification around high-quality schools (Wu, Q. et al., 2014). Jiaoyufication has much broader meanings. More distinctive characteristics of jiaoyufication (e.g., small household size, high proportion of school-age children, female and old adults, well-off middle-class parents, high residential mobility, low interest in housing refurbishment and neighborhood improvement) can be found in (Wu, Q. et al., 2014; Wu, Q., Zhang, \& Waley, 2016, 2017; Wu, Q., Edensor, \& Cheng, 2017).

Most pertinent literature concentrated on discussing and analyzing the xuequfang phenomenon from the perspectives of sociology, pedagogy or economics (Chen \& Tang, 2009; Wu, X., 2006). Relatively little research attention, to date, has been paid to empirically estimate the magnitude of the willingness-to-pay for highly regarded schools. Existing studies were found in a few cities: Beijing (Huang, 2010; Hu, Zheng, \& Wang, 2014), Shanghai (Feng \& Lu, 2010; Shi \& Wang, 2014), Nanjing (Wang, X., Ge, \& Zhang, 2010) and Tianjin (Wang, W. et al., 2014; Wang, Z., Mei, \& Wang, 2014). Moreover, many of them suffer from a few drawbacks, which reduces the credibility to some degree, such as unsatisfactory explanatory power (low goodness-of-fit) (Nie, 2011; Wang, X., Ge, \& Zhang, 2010; Wang, W. et al., 2014), inadequate control variables (Wang, W. et al., 2014) and limited sample size (Wang, W. et al., 2014).

Recently, a few studies have provided empirical cases in China with a more reliable explanation ( $\mathrm{Hu}$, Zheng, \& Wang, 2014; Shi \& Wang, 2014; Wang, Z., Mei, \& Wang, 2014; Wen, Zhang, \& Zhang, 2014; Jayantha \& Lam, 2015). Using data $(\mathrm{N}=1172)$ from a housing agency website (soufang), Shi and Wang (2014) discussed the impact mechanism of the xuequfang phenomenon in Shanghai and found that school factors accounted for $20.6 \%$ of the variability in residential property prices. They concluded that housing prices declined by $8.7 \%$ with a drop in the level of school grade. $\mathrm{Hu}$, Zheng, and Wang (2014) applied the boundary fixed effect method proposed by Black (1999) to control for neighborhood attributes, and used matching regression techniques to mitigate the omitted variable bias caused by unobservable neighborhood attributes. They reported that the prices of xuequfang are $8.1 \%$ higher in Beijing. Wang, Z., Mei, and Wang (2014) identified the capitalization of basic educational resources based on the second-hand housing data $(\mathrm{N}=1700)$ in Heping District, Tianjin, and reported that an increase of elementary school quality led to an $14.7 \%$ increase in housing prices. Using the housing data of 660 communities in Hangzhou, Wen, Zhang, and Zhang (2014) and Wen, Xiao, and Zhang (2017) examined the capitalization effect of the education quality on housing prices, and found that the quality of primary and secondary schools has been capitalized in the surrounding housing prices. 


\subsection{Research objectives, contributions and paper outline}

In this study, based on 1250 housing samples in 286 multi- or high-storey residential complexes in Xiamen Island, China, we develop a set of hedonic price models, more specifically, two basic and four Box-Cox transformed models to answer this question: are there capitalization benefits derived from high-quality schools in Xiamen Island, if so, what is the magnitude? Then, we discussed negative influences of the xuequfang phenomenon and proposed several countermeasures.

The main contributions of this paper are: (1) adding a reliable empirical study in the Chinese context about the quantitative valuation of high-quality schools to previously sparse literature; (2). comparing the performance of pre-specified functional forms with that of Box-Cox transformed models and revealing the great power of the Box-Cox transformation; (3). using propensity score matching technique to estimate the effect of high-quality school on housing prices; (4). shedding light on the mechanism of the xuequfang phenomenon and proposing some tentative countermeasures.

The remainder of this paper proceeds as follows. Section 2 introduces hedonic price model, Box-Cox transformation and propensity score matching. Section 3 presents the study area, data and variables; Section 4 presents the modeling results based on two pre-specified and four Box-Cox transformed functional forms, and further checks the plausibility of our key findings using propensity score matching. Section 5 discusses the negative influences of the demarcation of school attendance zone, and proposes some tentative countermeasures. Section 6 puts forward conclusions and further research directions.

\section{METHODOLOGY}

\subsection{Hedonic price model}

\subsubsection{Introduction}

From the perspective of the demand side of goods, hedonic price model is a celebrated method to appraise the determinant factors on prices of heterogeneous goods and estimate the implicit prices of attributes (Malpezzi, 2003). Hedonic prices are the implicit values of the attributes of a product, which can be empirically estimated from a multivariate regression equation.

Hedonic price model assumes that, in equilibrium, all consumers with identical preferences can achieve the same level of utility, which is measured as the price a person is willing to pay for the fulfillment or satisfaction of his/her desire. Lancaster (1966) defined utility in terms of the attributes of the goods and stated that what consumers are seeking to acquire is the characteristics embodied in the goods instead of goods themselves. In other words, a property is sold as a package of inherent attributes. Rosen (1974) presented that under the conditions of full market competition, the objectives of producers and consumers are to maximize profit and utility, respectively, and unfolded how markets work for heterogeneous goods.

Normally, the variables incorporated into hedonic price model can be categorized into three categories: structure, location, and neighborhood. Structure variables relate to the direct attributes of a property (e.g., floor area, age, number of bedrooms and bathrooms). Location variables reflect 
the ease with which amenities can be reached from a property (e.g., distance to city center, shopping center and hospital). Neighborhood variables describe the surrounding area of a property (e.g., income, education level, crime rate, and proximity to attractive school).

Hedonic price model explains the prices of properties in terms of their own characteristics, which are assumed to be implicitly priced. It has been widely used to estimate the implicit values of characteristics of properties and evaluate the contributions of a wide variety of factors, for instance, educational facilities (Sedgley, Williams, \& Derrick, 2008), shopping centers (Des Rosiers et al., 1996; Tse \& Love, 2000), hospitals (Peng, B. et al., 2015; Yang et al., 2016), public transportation (Cervero \& Duncan, 2002; Armstrong \& Rodriguez, 2006), green space (Luttik, 2000; Acharya \& Bennett, 2001; Kong, Yin, \& Nakagoshi, 2007), and population density (Geoghegan, 2002).

Recently, the rapid development of geographic information systems (GIS) has made hedonic price modeling more powerful because "spatial statistics within a GIS, based on digitized remote sensing data, have made possible the development of accurate, consistent, and unbiased explanatory variables...in a fast and efficient manner" ((Kong, Yin, \& Nakagoshi, 2007), p.241). With the help of GIS, many geo-related attributes can be precisely measured, which makes hedonic price modeling more easily, thereby increasing our understanding of the variations in residential property prices.

\subsubsection{Functional form choice}

Typically, hedonic price model applies multivariate regression techniques to relate property price details to diverse characteristics of different goods. Potentially, hedonic price model has a variety of functional forms. The linear model is the simplest model specification and the coefficients associated with independent variables are simply marginal changes, or prices per unit of characteristics, which are easy to be interpreted compared with other model specifications. It is as follows:

$P=f\left(X_{1}, X_{2}, \ldots, X_{n}\right)+\varepsilon=b+a_{1} X_{1}+a_{2} X_{2}+a_{3} X_{3}+\ldots+a_{n} X_{n}+\varepsilon$ where $P$ is price; $X_{1}, X_{2}, \ldots, X_{n}$ are the characteristics embodied in a property; $\varepsilon$ is random error term which reflects the unobserved variations in property prices; $a_{1}, a_{2}, \ldots, a_{n}$ are the regression coefficients; $b$ is a constant.

However, as Rosen (1974) states, there is no reason to assume that the relationship between the price and variables is linear. An apparent shortcoming of the linear model is the failure to reflect diminishing marginal utility. What's more, linear model imposes independence on the chosen explanatory variables (Halstead, Bouvier, \& Hansen, 1997). To the best of our knowledge, this model specification has been formulated less and less in the literature published in recent years.

Apart from the linear form, hedonic price model has two basic functional forms, both of which have been employed in a substantive number of studies:

(1). Semi-log model:

$$
\operatorname{In} P=b+a_{1} X_{1}+a_{2} X_{2}+a_{3} X_{3}+\ldots+a_{n} X_{n}+\varepsilon
$$

where dependent variables are in natural logarithms.

(2). Double-log model (log-linear model):

$$
\operatorname{In} P=b+a_{1} \operatorname{In} X_{1}+a_{2} \operatorname{In} X_{2}+a_{3} \operatorname{In} X_{3}+\ldots+a_{n} \operatorname{In} X_{n}+\varepsilon
$$

where both independent and dependent variables are in natural logarithms. 
Moreover, hedonic price model has a few flexible functional forms, such as trans-log form, semi-log quadratic form.

\subsection{Box-Cox transformation}

In some hedonic studies (Goodman, 1978; Halstead, Bouvier, \& Hansen, 1997; So, Tse, \& Ganesan, 1997; Yang, 2018), the Box-Cox transformation was used to choose among alternative functional forms in order to obtain the best-fitting non-linear model specification (with the highest goodness-of-fit value). Nevertheless, as Cassel and Mendelsohn (1985) indicate, applying a single "good-fit" criterion to select functional forms does not always lead to more accurate estimates of characteristic prices. As Ben-Akiva and Lerman (1985) pointed out, "a 'good fit' to data does not necessarily mean an adequate model, and it is not unusual to find several alternative model specifications that fit the data equally well. Moreover, a model can duplicate the data perfectly but give erroneous predictions" (p.154).

Although the application of the Box-Cox transformation in hedonic studies has suffered from some objections, it is still favored by a host of researchers as it addresses nonlinearity in model parameters. Very detailed information on the Box-Cox transformation can be found in Hossain (2011). Box-Cox models have a variety of functional forms, such as the simple lefthand-side model, simple right-hand-side model, simple both-side model and separate both-side model.

The simple left-hand-side Box-Cox model is as follows:

$$
Y^{(\lambda)}=X \beta+\varepsilon
$$

where $Y^{(\lambda)}=\left(Y^{\lambda}-1\right) / \lambda$ for $\lambda \neq 0$, whereas $Y^{(\lambda)}=\ln Y$ for $\lambda=0$.

The simple right-hand-side Box-Cox model is as follows:

$$
Y=X^{(\lambda)} \beta+\varepsilon
$$

where $X^{(\lambda)}=\left(X^{\lambda}-1\right) / \lambda$ for $\lambda \neq 0$, whereas $X^{(\lambda)}=\ln X$ for $\lambda=0$

The simple both-side Box-Cox model (same parameter for both sides) is as follows:

$$
Y^{(\lambda)}=X^{(\lambda)} \beta+\varepsilon
$$

where $Y^{(\lambda)}=\left(Y^{\lambda}-1\right) / \lambda, X^{(\lambda)}=\left(X^{\lambda}-1\right) / \lambda$ for $\lambda \neq 0$, whereas $Y^{(\lambda)}=\ln Y, X^{(\lambda)}=\ln X$ for $\lambda=0$.

The most general and flexible functional form, the separate both-side Box-Cox model (different parameters for both sides), is as follows:

$$
\begin{aligned}
& Y^{(\lambda)}=X^{(\theta)} \beta+\varepsilon \\
& \text { where } Y^{(\lambda)}=\left(Y^{\lambda}-1\right) / \lambda \text { for } \lambda \neq 0, X^{(\theta)}=\left(X^{\theta}-1\right) / \theta \text { for } \theta \neq 0, \\
& \text { whereas } Y^{(\lambda)}=\ln Y \text { for } \lambda=0, X^{(\theta)}=\ln X \text { for } \theta=0 .
\end{aligned}
$$

\subsection{Propensity score matching}

Despite the well-recognized usefulness of hedonic price functions, they still suffer from a few challenges, for example, functional form misspecification and omitted variable bias, which could lead to biased and inconsistent estimates. In this study, we decide to use propensity score 
matching technique to estimate the effect of high-quality school on property prices and compare its result with those of hedonic price models.

Matching is an important nonparametric pre-processing procedure for achieving balance and reducing bias as well as model dependence (Ho et al., 2007). Firstly proposed by Rosenbaum (1984), propensity score matching, which summarizes all explanatory variables with a single variable called propensity score (a balance score per se), is a widely used matching procedure in the statistical analysis of observational data. It selects comparable units of observation for estimation of the impacts of interventions by use of comparison group data. If the treatment (xuequfang here) and control (non-xuequfang here) groups have identical distributions of propensity score, all the covariates will be balanced between the two groups.

Propensity score matching procedures include: (1) dividing treated and control groups; (2) developing a Probit or binary logistic regression model (dependent variable $=1$ for treated observations; $=0$ for control observations) and estimating propensity score for each observation; (3) matching treatment and control observations based on their propensity scores according to some methods (e.g., nearest neighbour, kernel, exact, sub-classification); (4) estimating treatment effects, by either directly comparing the means or performing parametric outcome analysis.

\section{STUDY AREA AND DATA}

\subsection{Study area}

The study area is Xiamen Island, the central city of Xiamen. Xiamen is known as Amoy historically, located on the southeast coast of China with a total administrative area of $1699.39 \mathrm{~km}^{2}$ and a permanent population of 3.92 million in 2016 (Xiamen Statistics Bureau, 2017). Being termed as "Sea Garden", Xiamen is a famous livable and comfortable city in China.

Xiamen Island is the earliest developed area of Xiamen, and still remains the central city of Xiamen now. It is made up of Siming District and Huli District, owning a total of nearly $130 \mathrm{~km}^{2}$ land. The Jinmen Islands are less than 10 kilometers away. A significant feature differentiating Xiamen's city profile from the others is its unique status being located on the west coast of Taiwan Strait. Refer to Tang et al. (2013) for more detailed information on Xiamen Island and Xiamen City.

The reasons to choose Xiamen Island as our study area are as follows: on the one hand, traditional hedonic price models suffer from the omitted variable bias. An effective method to circumvent this problem is to focus on narrow geographic areas where many confounding variables can be properly controlled (Brasington, 2003). The scale and geographical features of Xiamen Island make it a tractable and ideal region for this study since the variations in many aspects are easy to control. On the other hand, GDP per person of Xiamen is 81.6 thousand yuan (RMB) in 2014 (Xiamen Statistics Bureau, 2014), which is higher than those of most Chinese cities. The life of residents in Xiamen Island is at a high economic level, which far exceeds the subsistence level. There is more disposable income that can be spent on other aspects such as housing. 


\subsection{Data}

There are very few new-built residential complexes in the highlydeveloped Xiamen Island now. Therefore, our sample is confined to secondhand residential properties for reasons of comparability. We do not consider terraced housing, villa, removal settlement buildings and affordable housing.

Data for this analysis come from two sources. The housing data set $(\mathrm{N}=1250)$ is the same as that in Yang et al. (2015), which was collected from the largest real estate agency websites of China, soufang.com, in April 2014. To collect data in a short period of time can effectively avoid the short-term fluctuation in price levels, thereby increasing the accuracy and credibility. 452 observations are from 106 residential complexes in Siming District while 798 observations are from 180 residential complexes in Huli District.

Apart from collecting housing samples, creating a workable GIS database is necessary. We used the data from the government official website or Baidu Map (a publicly available website) to establish the GIS database of Xiamen Island. All geo-related independent variables are quantified within the framework of ArcGIS.

Generally, the appraise of high-quality schools is based on these criteria: entering-school-rate (or shengxuelv in Chinese) or test scores of their students, educational outcomes, teachers and supporting facilities. In China, the differentiation between high-quality and normal (that is, medium- and low-quality) schools is substantially simpler relative to Western countries. It is widely accepted that provincial-level demonstration elementary schools granted by the Education Department (or jiaoyuting in Chinese) of provincial government are highly regarded schools. We follow this approach in our study.

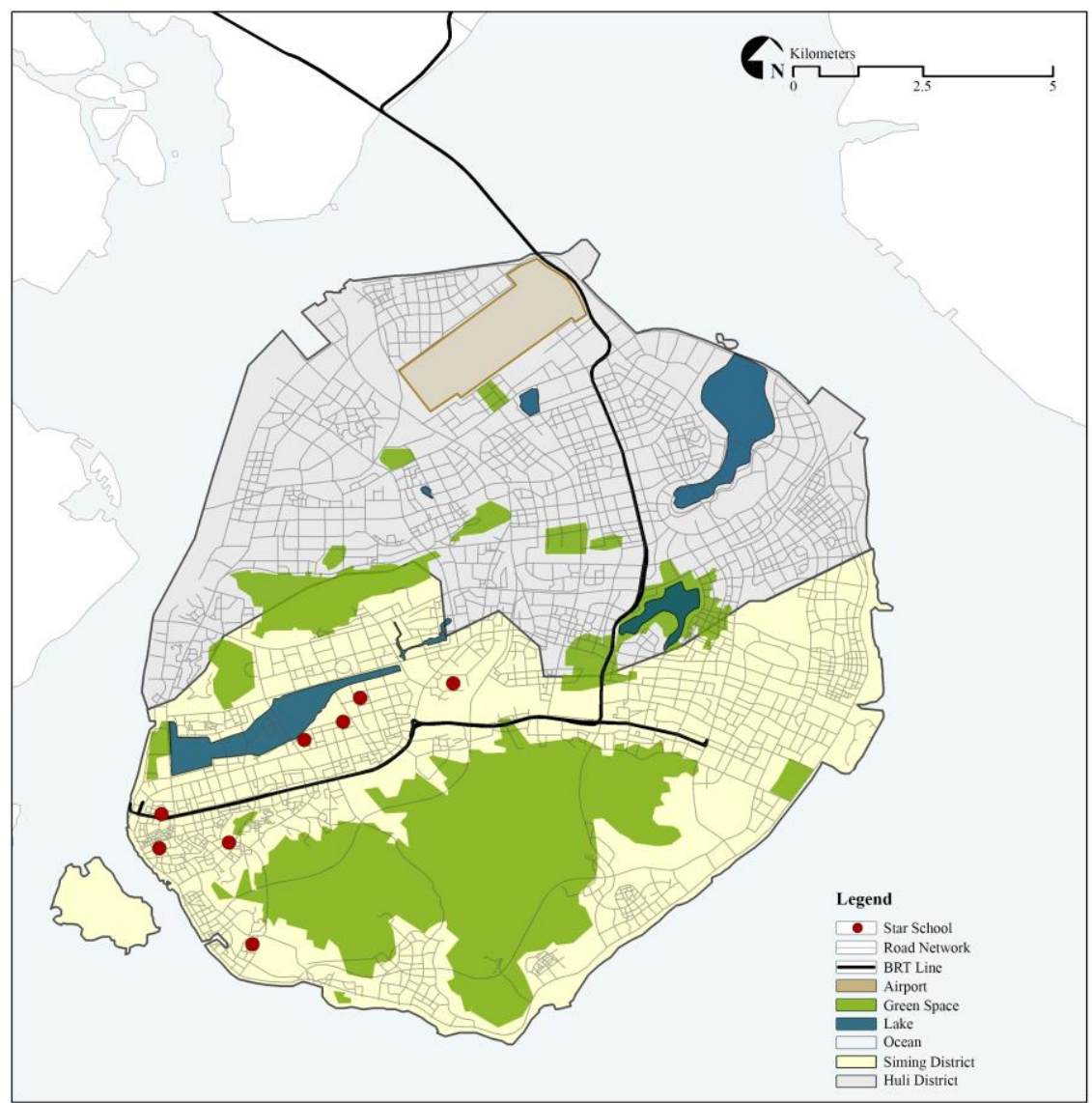

Figure 1. High-quality schools in Xiamen Island 
Until 2015, there were eight provincial-level demonstration elementary schools in Xiamen Island (Fig.1). They are Yanwu Elementary School, Minli Elementary School, Experimental Elementary School, Second Experimental Elementary School, Datong Elementary School, Affiliated elementary school of Foreign Language School, Bindong Elementary School and Binlang Elementary School. It is noteworthy that all of them are situated in the west of Siming District, which reveals the apparent spatial variations and imbalance.

\subsection{Variables}

Table 1 shows the definitions and descriptive statistics of twelve independent variables. Except for School, all other eleven independent variables are theoretically important variables that need to be statistically controlled for by being included in our regression models. It should be noted that a variable widely used in the western literature, number of bedrooms, was not included in our regression models, in the interest of model parsimony, because its effect would overlap with floor area, resulting in the presence of multi-collinearity (So, Tse, \& Ganesan, 1997). Moreover, job accessibility is not introduced due to the unavailability of data.

Table 1. Variable Definitions and Descriptive Statistics

\begin{tabular}{|c|c|c|c|c|}
\hline Variable & Description & $\begin{array}{l}\text { Expected } \\
\text { sign }^{1}\end{array}$ & Mean & SD \\
\hline Area & Gross floor area $\left(\mathrm{m}^{2}\right)$ & + & 105.69 & 43.02 \\
\hline Age & $\begin{array}{l}2015 \text { minus the year of occupation permit } \\
\text { (number of years) }\end{array}$ & - & 12.13 & 4.81 \\
\hline $\begin{array}{l}\text { Local } \\
\text { environment }\end{array}$ & $\begin{array}{l}\text { Environment quality of residential } \\
\text { complexes the property, rated on a 5-point } \\
\text { Likert item from "very bad" (1) to "very } \\
\text { good" (5) }\end{array}$ & + & 3.08 & 0.93 \\
\hline School & $\begin{array}{l}\text { Dummy variable, } 1 \text { if the property is } \\
\text { xuequfang, } 0 \text { otherwise }\end{array}$ & + & 0.13 & 0.33 \\
\hline Kindergarten & $\begin{array}{l}\text { Dummy variable, } 1 \text { if there are at least one } \\
\text { kindergarten within } 500 \text { meters, } 0 \text { otherwise }\end{array}$ & + & 0.83 & 0.37 \\
\hline Middle school & $\begin{array}{l}\text { Dummy variable, } 1 \text { if there are at least one } \\
\text { middle school within } 1000 \text { meters, } 0 \\
\text { otherwise }\end{array}$ & + & 0.82 & 0.38 \\
\hline $\begin{array}{l}\text { Xiamen } \\
\text { University }\end{array}$ & $\begin{array}{l}\text { Dummy variable, } 1 \text { if Xiamen University is } \\
\text { within } 1000 \text { meters, } 0 \text { otherwise }\end{array}$ & + & 0.02 & 0.13 \\
\hline BRT & $\begin{array}{l}\text { Dummy variable, } 1 \text { if there are at least one } \\
\text { BRT (Bus Rapid Transit) station within } 800 \\
\text { meters, } 0 \text { otherwise }\end{array}$ & + & 0.23 & 0.42 \\
\hline $\begin{array}{l}\text { Distance to } \\
\text { hospital }\end{array}$ & $\begin{array}{l}\text { Euclidean distance to the nearest Class } 2 \mathrm{~A} \text { or } \\
3 \mathrm{~A} \text { hospital }(\mathrm{km})\end{array}$ & $?$ & 0.81 & 0.77 \\
\hline $\begin{array}{l}\text { Distance to } \\
\text { cultural/sports } \\
\text { center }\end{array}$ & $\begin{array}{l}\text { Euclidean distance to the nearest } \\
\text { cultural/sports center }(\mathrm{km})\end{array}$ & - & 1.11 & 0.66 \\
\hline $\begin{array}{l}\text { Distance to } \\
\text { city center }\end{array}$ & $\begin{array}{l}\text { Euclidean distance to Zhongshan Road, the } \\
\text { city center of Xiamen Island }(\mathrm{km})\end{array}$ & - & 6.84 & 2.57 \\
\hline $\begin{array}{l}\text { Distance to } \\
\text { lake }\end{array}$ & Euclidean distance to the nearest lake $(\mathrm{km})$ & - & 1.08 & 0.68 \\
\hline
\end{tabular}

Note: ${ }^{\mathrm{a}}+$ and - represent increasing and decreasing impacts on housing prices respectively; ? indicates a priori undetermined sign. 


\section{RESULTS}

\subsection{Initial hedonic price regression}

EVIEWS 9 is used to build a semi-log and a double-log model using the ordinary least squares (OLS) method. The dependent variable is modified by a natural $\log$ transformation in both models whereas independent variables are modified by a natural log transformation only in the double-log model. We do not transform five dummy variables as they are not definitely greater than 0 . Table 2 provides the modeling results. The goodness-of-fit values of both models $(0.801,0.850)$ are higher than that based on the same data source in Yang et al. (2015) (0.789). This indicates that the two models were able to predict higher proportions of variability in their outcomes compared to the model in Yang et al. (2015). Moreover, with a higher model fit, the double-log model outperforms the semi-log model, which indicates that it captures more variations in housing prices. All but two variables are significant at the 5\% level in both models. Kindergarten and Middle school are not significant at the 5\% level, which implies that they are not associated with housing prices.

Table 2. Regression results of semi-log and double-log models

\begin{tabular}{|c|c|c|c|c|}
\hline \multirow[t]{2}{*}{ Variable } & \multicolumn{2}{|c|}{ Semi-log model } & \multicolumn{2}{|c|}{ Double-log model } \\
\hline & coefficient & t-value & coefficient & t-value \\
\hline Constant & $4.579^{\mathrm{a}}$ & 88.67 & $1.091^{\mathrm{a}}$ & 13.89 \\
\hline Area & $0.010^{\mathrm{a}}$ & 59.16 & $1.008^{\mathrm{a}}$ & 70.70 \\
\hline Age & $-0.011^{\mathrm{a}}$ & -7.65 & $-0.153^{\mathrm{a}}$ & -11.26 \\
\hline Local environment & $0.068^{\mathrm{a}}$ & 8.36 & $0.177^{\mathrm{a}}$ & 7.94 \\
\hline School & $0.089^{a}$ & 4.00 & $0.108^{a}$ & 5.45 \\
\hline Kindergarten & $0.009^{c}$ & 0.47 & $-0.011^{\mathrm{c}}$ & -0.68 \\
\hline Middle school & $-0.001^{\mathrm{c}}$ & -0.06 & $0.032^{\mathrm{c}}$ & 1.91 \\
\hline Xiamen University & $0.206^{\mathrm{a}}$ & 3.45 & $0.144^{\mathrm{a}}$ & 3.04 \\
\hline BRT & $0.077^{\mathrm{a}}$ & 4.72 & $0.100^{\mathrm{a}}$ & 6.85 \\
\hline Distance to hospital & $0.047^{\mathrm{a}}$ & 4.41 & $0.018^{\mathrm{b}}$ & 2.13 \\
\hline Distance to cultural/sports center & $-0.057^{\mathrm{a}}$ & -5.04 & $-0.049^{\mathrm{a}}$ & -5.25 \\
\hline Distance to city center & $-0.021^{\mathrm{a}}$ & -6.04 & $-0.077^{a}$ & -6.36 \\
\hline Distance to lake & $-0.072^{\mathrm{a}}$ & -6.06 & $-0.051^{\mathrm{a}}$ & -5.95 \\
\hline \multicolumn{5}{|l|}{ Performance statistics } \\
\hline Adjusted $\mathrm{R}^{2}$ & 0.801 & & 0.850 & \\
\hline Log-likelihood & 66.00 & & 238.69 & \\
\hline AIC & -0.09 & & -0.37 & \\
\hline
\end{tabular}

Note: ${ }^{\mathrm{a}}$ significant at the $1 \%$ level. ${ }^{\mathrm{b}}$ significant at the $5 \%$ level. ${ }^{\mathrm{c}}$ not significant at the $5 \%$ level.

With no exception, the signs of all variables' coefficients agree with $a$ priori expectation. The coefficients associated with Area, Local environment, School, Xiamen University, BRT are positive. This implies that properties with larger size, having better local environment and BRT access, within attendance zone of a high-quality school and closer to Xiamen University, exhibit higher values. The coefficients of Age, Distance to cultural/sports center, Distance to city center, Distance to lake, have the 
hypothesized negative signs. It indicates that houses at the younger age, with better accessibility to the city center, culture/sports center and lake, are more expensive, all else being fixed.

The coefficient associated with Distance to hospital is positive, which indicates that proximity to Class $2 \mathrm{~A}$ and $3 \mathrm{~A}$ hospitals negatively affects housing prices. This indicates the nuisance effect of being located near hospitals, which seems somewhat surprising, but consistent with the findings in Li et al. (2013) and Peng, B. et al. (2015). There are two possible explanations. Firstly, different age cohorts have differing needs and preferences of services, for example health care services (Wong et al., 2018). Normally, young adults seldom go to hospital, so they may not consider proximity to hospitals when making residential location decisions, even tend to live far away from hospitals. Notwithstanding, the elderly are in general more likely to go to hospital (Yang, 2016; Szeto et al., 2017; Wong et al., 2017) and may tend to live close to hospitals for better access due to higher visiting frequency ( $\mathrm{Li}$ et al., 2013). In addition, it is crowded around highlevel comprehensive hospitals generally. There are a huge number of people and vehicles within these regions, generating noises and air pollution, thereby reducing nearby residents' quality of life (Peng, B. et al., 2015).

The coefficients of the double-log regression function correspond to average attribute elasticities. Gross floor area is found to be the dominating elemental attribute, which has the greatest influence on housing prices as hypothesized. In addition, being located in the attendant zone of a highquality school has nearly the same positive impact on housing prices as access to BRT (0.108 vs 0.100). Furthermore, among four location variables, Distance to city center exhibits the largest impact on housing prices, which is consistent with the bid-rent theory proposed by Alonso (1964).

\subsection{Box-Cox transformation}

For further checking the robustness of variables, four Box-Cox functions are estimated. All functional forms represent relatively simple applications of the Box-Cox transformation: the simple left-hand-side Box-Cox model; the simple right-hand-side Box-Cox model; the simple both-side Box-Cox model; the separate both-side Box-Cox model. It should be noted that we do not transform five dummy independent variables as they are not definitely positive.

Table 3 shows the results and reveals that the most flexible form, the separate both-side Box-Cox model, outperforms other three Box-Cox models. It has the lowest AIC (Akaike information criterion) value and the greatest adjusted $\mathrm{R}^{2}$ and Log-likelihood.

The levels of statistical significance of all twelve independent variables are consistent in all six model specifications (two pre-specified and four Box-Cox transformed models). Kindergarten and Middle school are not associated with housing prices while other variables significantly affect housing prices (significant at the 5\% level). This implies that our hedonic price models (both pre-specified and Box-Cox transformed) can explain price variations well and the variables included do affect housing prices. In addition, the signs of all coefficients are in line with expected.

Table 3. Results of four Box-Cox transformed functional forms

\begin{tabular}{|c|c|c|c|c|}
\hline Variables & $\begin{array}{l}\text { Simple LHS } \\
\text { Box-Cox } \\
\text { model: }\end{array}$ & $\begin{array}{l}\text { Simple RHS } \\
\text { Box-Cox } \\
\text { model: }\end{array}$ & $\begin{array}{l}\text { Simple both- } \\
\text { side Box-Cox } \\
\text { model: }\end{array}$ & $\begin{array}{l}\text { Separate both- } \\
\text { side Box-Cox } \\
\text { model: }\end{array}$ \\
\hline
\end{tabular}




\begin{tabular}{|c|c|c|c|c|}
\hline & $\begin{array}{l}\text { coefficient (t- } \\
\text { value) }\end{array}$ & $\begin{array}{l}\text { coefficient (t- } \\
\text { value) }\end{array}$ & $\begin{array}{l}\text { coefficient (t- } \\
\text { value) }\end{array}$ & $\begin{array}{l}\text { coefficient (t- } \\
\text { value) }\end{array}$ \\
\hline Constant & $9.784(34.54)^{\mathrm{a}}$ & $58.907(5.20)^{\mathrm{a}}$ & $1.137(12.87)^{\mathrm{a}}$ & $1.618(19.41)^{\mathrm{a}}$ \\
\hline Area & $0.055(63.53)^{\mathrm{a}}$ & $1.429(59.11)^{\mathrm{a}}$ & $1.035(70.56)^{\mathrm{a}}$ & $0.833(70.52)^{\mathrm{a}}$ \\
\hline Age & $-0.074(-9.30)^{\mathrm{a}}$ & $\begin{array}{l}-3.044(- \\
10.17)^{\mathrm{a}}\end{array}$ & $\begin{array}{l}-0.169(- \\
11.32)^{\mathrm{a}}\end{array}$ & $\begin{array}{l}-0.151(- \\
11.20)^{\mathrm{a}}\end{array}$ \\
\hline Local environment & $0.434(9.36)^{\mathrm{a}}$ & $16.629(8.05)^{\mathrm{a}}$ & $0.203(8.00)^{\mathrm{a}}$ & $0.195(8.01)^{\mathrm{a}}$ \\
\hline School & $0.616(5.14)^{\mathrm{a}}$ & $36.359(5.90)^{\mathrm{a}}$ & $0.128(5.48)^{\mathrm{c}}$ & $0.129(5.46)^{\mathrm{c}}$ \\
\hline Kindergarten & $-0.005(-0.05)^{\mathrm{c}}$ & $-4.621(-0.88)^{\mathrm{c}}$ & $-0.013(-0.70)^{\mathrm{c}}$ & $-0.013(-0.67)^{\mathrm{c}}$ \\
\hline Middle school & $0.029^{\mathrm{a}}(0.28)^{\mathrm{c}}$ & $4.011(0.76)^{\mathrm{c}}$ & $0.036(1.84)^{\mathrm{a}}$ & $0.033(1.70)^{\mathrm{a}}$ \\
\hline Xiamen University & $0.990(3.09)^{\mathrm{b}}$ & $42.604(2.53)^{\mathrm{b}}$ & $0.170(3.04)^{\mathrm{a}}$ & $0.172(3.03)^{\mathrm{a}}$ \\
\hline BRT & $0.429(4.93)^{\mathrm{a}}$ & $19.596(4.38)^{\mathrm{a}}$ & $0.117(6.81)^{\mathrm{a}}$ & $0.116(6.72)^{\mathrm{a}}$ \\
\hline Distance to hospital & $0.252(4.47)^{\mathrm{a}}$ & $11.195(4.06)^{\mathrm{a}}$ & $0.022(2.16)^{\mathrm{b}}$ & $0.023(2.21)^{\mathrm{b}}$ \\
\hline $\begin{array}{l}\text { Distance to } \\
\text { cultural/sports center }\end{array}$ & $-0.294(-4.71)^{\mathrm{a}}$ & $\begin{array}{l}-12.988(- \\
4.16)^{\mathrm{a}}\end{array}$ & $-0.059(-5.31)^{\mathrm{a}}$ & $-0.062(-5.39)^{\mathrm{a}}$ \\
\hline $\begin{array}{l}\text { Distance to city } \\
\text { center }\end{array}$ & $-0.134(-7.26)^{\mathrm{a}}$ & $-5.477(-7.12)^{\mathrm{a}}$ & $-0.088(-6.37)^{\mathrm{a}}$ & $-0.084(-6.28)^{\mathrm{a}}$ \\
\hline Distance to lake & $-0.345(-5.42)^{\mathrm{a}}$ & $\begin{array}{l}-10.734(- \\
3.32)^{\mathrm{a}}\end{array}$ & $-0.061(-5.99)^{\mathrm{a}}$ & $-0.063(-5.99)^{\mathrm{a}}$ \\
\hline $\begin{array}{l}\text { Left-hand side } \\
\text { parameter } \\
\text { Right-hand side }\end{array}$ & $0.317(11.41)^{\mathrm{a}}$ & - & - & $0.032(1.02)^{c}$ \\
\hline $\begin{array}{l}\text { Right-hand side } \\
\text { parameter } \\
\text { Both-hand side }\end{array}$ & - & $1.128(19.03)^{\mathrm{a}}$ & - & $0.080(1.45)^{\mathrm{c}}$ \\
\hline $\begin{array}{l}\text { Both-hand side } \\
\text { parameter }\end{array}$ & - & - & $0.030(0.95)^{\mathrm{c}}$ & - \\
\hline \multicolumn{5}{|l|}{ Performance statistics. } \\
\hline Adjusted $\mathrm{R}^{2}$ & 0.826 & 0.806 & 0.851 & 0.851 \\
\hline Log-likelihood & -1999.85 & -6864.68 & 39.83 & 26.60 \\
\hline AIC & 3.26 & 11.15 & -0.04 & -0.02 \\
\hline
\end{tabular}

Note: ${ }^{\mathrm{a}}$ significant at the $1 \%$ level. ${ }^{\mathrm{b}}$ significant at the $5 \%$ level. ${ }^{\mathrm{c}}$ not significant at the $5 \%$ level.

\subsection{Propensity score matching}

The "MatchIt" package in R constructs ( treatment effects estimation. The model employed to estimate propensity score, defined as the probability of receiving treatment, conditional on the covariates, is a binary logistic regression model. The explanatory variables used for logistics regression are the same as those used for the hedonic price function estimates. There are 158 treatment and 1092 control observations in our data set. The matching method we use is "optimal" matching, which seeks out the matched observations with the smallest total absolute distance within matched units. This method (i.e., "optimal" matching) is, in nature, strikingly different from "greedy" matching, which starts with some treated units and matches the closest control unit that has not yet been matched, without trying to minimize a global distance measure, so it efficiently avoids a problem of "greedy" matching, variant to the order in which units are matched (Ho et al., 2007).

After matching, we compare the difference between the means for each explanatory variable in full samples and matched samples and find that matching does greatly enhance the balance of covariates. The estimation of the treatment effect reveals that the residential properties being located within high-quality school attendance zones (xuequfang) are $12.1 \%$ higher than the properties located outside of these areas (non-xuequfang), all else keeping fixed. 


\subsection{High-quality school value premiums}

The following interpretation of the value premiums offered by highquality schools is based on the semi- and double-log hedonic price models developed and propensity score matching. The coefficient of School in the semi- and double-log model is 0.089 and 0.108 , respectively. This indicates that residential properties being located within high-quality school attendance zones (xuequfang) exhibit values that are between $9.3 \%\left(=\mathrm{e}^{0.089}\right.$ 1) and $11.4 \%\left(=\mathrm{e}^{0.108}-1\right)$ higher than the properties located outside of these areas (non-xuequfang), ceteris paribus. The value premium estimation provided by propensity score matching $(12.1 \%)$ is very consistent with the hedonic price regression results.

The magnitude of the price premium offered by high-quality school of Xiamen Island is a little higher than that estimated in Beijing $(8.1 \%)(\underline{\mathrm{Hu}}$, Zheng, \& Wang, 2014) and Shanghai $(8.7 \%, 9.7 \%$ ) (Shi \& Wang, 2014; Peng, B. et al., 2015), but lower than that in Tianjin (14.7\%) (Wang, Z., Mei, \& Wang, 2014) and Hong Kong (39.4\%, 27.3\%) (Jayantha \& Lam, 2015).

\section{DISCUSSIONS}

According to the pedagogy theory, four factors - genetics, environment, school and subjective initiative - can affect the physical and mental development of people. Among them, only environment and school are space-relevant. The former involves loads of factors, with family environment accounting for a major proportion, while school is a very important factor which parents can do something for the physical and mental development of their children.

The demarcation of school attendance zones is based on many factors such as school distribution, population distribution and natural boundary. It is, originally, to ensure the accessibility and security of school-age children. However, since elementary schools show exceptional heterogeneity (obvious disparities, tremendous diversity) in some aspects such as test performance and entering-school rate, parents' expectation would deviate from the reality in terms of school choices. That is, assuming that a child with local hukou registered in the attendance zone of school $\mathrm{A}$ wants to attend school $\mathrm{B}$, it is very difficult, if not impossible, according to strict policy of entrance from attendance zones alone, however. So, in most cases, parents need to buy a residence in the attendance zone of school B. As a result, the imbalance of inadequate supply and growing demand leads to the higher prices of xuequfang. For example, in Nanjing, the supply-demand ratio of xuequfang reaches 10 (Chen \& Tang, 2009). Obviously, the advent of the xuequfang phenomenon is in stark contrast to original goals of school attendance zone demarcation.

According to Chen and Tang (2009), there are a series of negative effects of the xuequfang phenomenon: (1) unfair educational resource allocation. Coupled with the advancement of the nation, education is no longer regarded as a privilege. Good educational resources are expected to be unfairly allocated and driven by the market mechanism. The introduction of territorial-based school admission policy which links educational resources with residential properties, distorts the market. As a result, the better the nearby educational resources are, the higher value the housing exhibits. This turns out that the rich can still obtain high-quality educational 
resources with their economic advantages, while the poor have few chances to get access to a prestigious school. Therefore, socio-economic polarization would be reinforced and then fixed in place ( $\mathrm{Wu}, \mathrm{Q}$., Zhang, \& Waley, 2016). (2) formulating spatial barriers and separating different income groups. The school attendance zone demarcation and the dramatic housing price gap have gradually exerted influence on urban form and led to the isolation of communities. Like some invisible barriers, the poor quarter and the wealthy neighborhood may be imperceptibly partitioned by different school attendance zones. This may hamper the communication and interaction among different income groups, thereby ruining social harmony and stability. This results in the Matthew effect of the rich and poor. (3) extruding consumer market. People have stable disposable income, but spend a great amount on xuequfang. This decreases household expenses in other areas, such as food, clothes, tour, which would affect the development of other industries and consumer market. With family wealth rising and living conditions improving constantly, people have a higher requirement for living space and housing. Yet, real estate market grows in an unhealthy way due to the xuequfang phenomenon.

Based on the aforementioned analysis, a few countermeasures can be discussed: (1) reforming household registration system (HRS) gradually. Although HRS is a major tool of social control adopted by the state and has historical contributions (e.g., economic development, social stability) (Cheng \& Selden, 1994; Chan \& Zhang, 1999), it is associated with the discriminative provision of social welfare (including education). Its potential reform has drawn the extensive attention of scholars and policy makers. The reform should not be achieved in a short period of time, but proceed in a gradual manner (Zhao, 2003; Yang \& Hong, 2013). Directly deregulating or eliminating the limitation of population migration may not be appropriate. Removing the social welfare provision functions of HRS, transforming it from a (discriminative) status-checking system to one that basically registers people's residency statuses and linking social welfare to common citizenship (instead of discriminative hukou) is thereby suggested (Peng, X., Zhao, \& Guo, 2009). (2) optimizing the resource distribution to balance the quality of education. The scarcity and unequal distribution of good educational resources give rise to the xuequfang phenomenon, constituting the biggest hindrance to the development of education. As people rush to purchase a xuequfang, education and real estate industry grow abnormally. Accordingly, homogenizing educational resources and flattening school gap become rather imperative. To achieve educational equity and balance resource allocation, appropriately boosting education investment is essential and feasible as it helps optimize facilities and improves teaching environment. (3) highlighting family education and children's all-round development. Obviously, not all excellent students graduated from prestigious schools. Indeed, school is an essential external factor that shapes a child. Many internal factors such as family education and subjective initiative, are also important to the success of a child. Even in the ancient time characterized by material deprivation, poor environments brought up a batch of extraordinary people as well. Therefore, conducting family education, focusing more on character and moral advancement, teaching children in accordance with their aptitude and activate their selfconsciousness of success become necessary. Blindly following talentcultivating objectives by purchasing a xuequefang are not be acceptable. 


\section{CONCLUDING REMARKS}

In China, due to the scarcity of high-quality schools, the household registration system and the territorial-based school admission policy, a feasible way for parents to offer high-quality education to the next generation is to buy a xuequfang. The supply-demand imbalance leads to the xuequfang phenomenon. Higher prices of xuequfang contain parents' investment in children's future.

Using Xiamen Island as a case study, this study empirically appraises the value that parents place on school quality by estimating how much residents are willing to pay for a xuequfang based on a set of hedonic price models, more specifically, two pre-specified and four Box-Cox transformed models, and the propensity score matching technique. The results indicate that these two approaches play complementary roles in data analysis. Our study adds an empirical study in the Chinese context about the quantitative valuation of high-quality school attendance zones to previous sparse literature, and demonstrates that xuequfang exhibit values that are $9.3 \%$ to $12.1 \%$ higher than non-xuequfang, all else keeping constant. High-quality school does generate a premium that is reflected in property prices, and homebuyers' willingness-to-pay for high-quality school can be clearly identified. Overall, our models are satisfactory: the signs of all parameters are consistent with $a$ priori expectation, and their levels of statistical significance are consistent in all six models. They have been proved to have a very significant and consistent explanatory power. The value premium estimation provided by propensity score matching $(12.1 \%)$ is very consistent with the hedonic price regression results. The issues pertinent to the xuequfang phenomenon has been discussed including school attendance zone demarcation, its negative influences, and countermeasures.

This study has several limitations which deserve further research. Firstly, our study failed to account for the obvious spatial effect (spatial autocorrelation) in data. The spatial regression can be used to take account of this. Secondly, due to the absence of rich data, some potentially contributory factors (e.g., floor area ratio, property management fee, population density), were not included in our models. Thirdly, due to data limitation, we used Euclidean distance (shortest distance, straight-line distance) to measure the accessibility of geographical elements instead of network distance (real-life distance). Last but not least, to reflect travel frictions, geographical distances (instead of travel times) are used. Actually, for residents, the perception of travel time might be more important than travel distance in determining mode choice. Cervero (2005) notes that accessibility is a product of mobility and proximity. In this regard, our study simply considered proximity, but ignored mobility. It is a weakness of most of existing literature. Calculating travel time by differing transport modes (e.g., walking, cycling, public transportation, automobile) under different conditions (at least, during the peak and non-peak hours) to reflect accessibility and incorporating these metrics into hedonic price models may yield more detailed results.

\section{ACKNOWLEDGEMENT}

This paper is the enhanced version of our original paper, The Effect of High-quality School Districts on Residential Property Prices in the Chinese Context, published in The Proceedings of International Conference 2015 on 
Spatial Planning and Sustainable Development. We are grateful to editors for giving us this opportunity to disseminate our research and ideas. Also, we would like to sincerely express our gratitude to Geng Cheng, the urban planner at Hefei Urban Planning \& Design Institute for his constructive comments and suggestions, which help enhances the quality of this paper substantially.

\section{REFERENCES}

Acharya, G., \& Bennett, L. L. (2001). "Valuing Open Space and Land-Use Patterns in Urban Watersheds". The Journal of Real Estate Finance and Economics, 22(2), 221-237.

Alonso, W. (1964). Location and Land Use. Toward a General Theory of Land Rent. Cambridge: Harvard University Press.

Armstrong, R. J., \& Rodriguez, D. A. (2006). "An Evaluation of the Accessibility Benefits of Commuter Rail in Eastern Massachusetts Using Spatial Hedonic Price Functions". Transportation, 33(1), 21-43.

Ben-Akiva, M. E., \& Lerman, S. R. (1985). Discrete Choice Analysis: Theory and Application to Travel Demand. Cambridge, Massachusetts: MIT press.

Black, S. E. (1999). "Do Better Schools Matter? Parental Valuation of Elementary Education". The Quarterly Journal of Economics, 114(2), 577-599.

Brasington, D. M. (2003). "The Supply of Public School Quality". Economics of Education Review, 22(4), 367-377.

Cassel, E., \& Mendelsohn, R. (1985). "The Choice of Functional Forms for Hedonic Price Equations: Comment". Journal of Urban Economics, 18(2), 135-142.

Cervero, R. (2005). "Accessible Cities and Regions: A Framework for Sustainable Transport and Urbanism in the 21st Century": UC Berkeley Center for Future Urban Transport: A Volvo Center of Excellence. Retrieved from https://escholarship.org/content/qt27g2q0cx/qt27g2q0cx.pdf.

Cervero, R., \& Duncan, M. (2002). "Transit's Value-Added Effects: Light and Commuter Rail Services and Commercial Land Values". Transportation Research Record: Journal of the Transportation Research Board, (1805), 8-15.

Chan, K. W., \& Zhang, L. (1999). "The Hukou System and Rural-Urban Migration in China: Processes and Changes". The China Quarterly, 160, 818-855.

Chen, L., \& Tang, X. (2009). "Reasons of the Xuequfang Phenomenon and Its Spillover Effect". China Collective Economy, (25), 95-96.

Cheng, T., \& Selden, M. (1994). "The Origins and Social Consequences of China's Hukou System". The China Quarterly, 139, 644-668.

Clapp, J. M., Nanda, A., \& Ross, S. L. (2008). "Which School Attributes Matter? The Influence of School District Performance and Demographic Composition on Property Values". Journal of Urban Economics, 63(2), 451-466.

Des Rosiers, F., Lagana, A., Thériault, M., \& Beaudoin, M. (1996). "Shopping Centres and House Values: An Empirical Investigation". Journal of Property Valuation and Investment, 14(4), 41-62.

Feng, H., \& Lu, M. (2010). "Selecting School by Buying Houses: Evidence and Policy Implication". The Journal of World Economy, (12), 89-104.

Geoghegan, J. (2002). "The Value of Open Spaces in Residential Land Use". Land Use Policy, 19(1), 91-98.

Goodman, A. C. (1978). "Hedonic Prices, Price Indices and Housing Markets". Journal of Urban Economics, 5(4), 471-484.

Halstead, J. M., Bouvier, R. A., \& Hansen, B. E. (1997). "On the Issue of Functional Form Choice in Hedonic Price Functions: Further Evidence". Environmental Management, 21(5), 759-765.

Hayes, K. J., \& Taylor, L. L. (1996). "Neighborhood School Characteristics: What Signals Quality to Homebuyers?". Economic Review-Federal Reserve Bank of Dallas, (Fourth Quarter), 2-9.

Ho, D. E., Imai, K., King, G., \& Stuart, E. A. (2007). "Matching as Nonparametric Preprocessing for Reducing Model Dependence in Parametric Causal Inference". Political analysis, 15(3), 199-236.

Ho, D. E., Imai, K., King, G., \& Stuart, E. A. (2011). "Matchit: Nonparametric Preprocessing for Parametric Causal Inference". Journal of Statistical Software, 42(8), 1-28. 
Hossain, M. Z. (2011). "The Use of Box-Cox Transformation Technique in Economic and Statistical Analyses". Journal of Emerging Trends in Economics and Management Sciences, 2(1), 32-39.

Hu, W., Zheng, S., \& Wang, R. (2014). "The Capitalization of School Quality in Home Value: A Matching Regression Approach with Housing Price-Rent Comparison". China Economic Quarterly, 13(3), 1195-1214.

Huang, B. (2010). "The Impact of Education Facilities on Residential Property Prices: A Case Study of the Affiliated Elementary School of Renmin University of China". Consume Guide, (2), 58-60.

Jayantha, W. M., \& Lam, S. O. (2015). "Capitalization of Secondary School Education into Property Values: A Case Study in Hong Kong". Habitat International, 50, 12-22.

Kong, F., Yin, H., \& Nakagoshi, N. (2007). "Using Gis and Landscape Metrics in the Hedonic Price Modeling of the Amenity Value of Urban Green Space: A Case Study in Jinan City, China". Landscape and Urban Planning, 79(3), 240-252.

Lancaster, K. J. (1966). "A New Approach to Consumer Theory". Journal of political economy, 74(2), 132-157.

Li, Y., He, L., Xu, W., Wang, H., \& He, Z. (2013). "Using Gis and Hedonic in the Modelling of Spatial Variation of Housing Price in Xiamen City". International Review for Spatial Planning and Sustainable Development, 1(4), 29-42.

Luttik, J. (2000). "The Value of Trees, Water and Open Space as Reflected by House Prices in the Netherlands". Landscape and Urban Planning, 48(3), 161-167.

Malpezzi, S. (2003). "Hedonic Pricing Models: A Selective and Applied Review". Housing Economics and Public Policy, 67-89.

Nie, F. (2011). "The Influence of Key Primary and Secondary School on Ordinary Housing Price: A Case Study of Banding". (Master), Agricultural University of Hebei Province.

Peng, B., Shi, Y., Shan, Y., \& Chen, D. (2015). "The Spatial Impacts of Class 3a Comprehensive Hospitals on Peripheral Residential Property Prices in Shanghai". Scientia Geographica Sinica, 35(7), 860-866.

Peng, X., Zhao, D., \& Guo, X. (2009). "The Reform of China's Household Registration System: A Political Economics View". Fudan Journal (Social Sciences Edition), 3, 1-11.

Rosen, S. (1974). "Hedonic Prices and Implicit Markets: Product Differentiation in Pure Competition". Journal of Political Economy, 82(1), 34-55.

Rosenbaum, P. R. (1984). "The Consequences of Adjusting for a Concomitant Variable That Has Been Affected by Treatment". Journal of the Royal Statistical Society. Series A, 147(5), 656-666.

Sedgley, N. H., Williams, N. A., \& Derrick, F. W. (2008). "The Effect of Educational Test Scores on House Prices in a Model with Spatial Dependence". Journal of Housing Economics, 17(2), 191-200.

Shi, Y.-S., \& Wang, Y.-T. (2014). "The Impacting Mechanism of Housing Prices in the School Districts in Shanghai City". China Land Sciences (Social Sciences), 17, 47-55.

So, H., Tse, R. Y., \& Ganesan, S. (1997). "Estimating the Influence of Transport on House Prices: Evidence from Hong Kong". Journal of Property Valuation and Investment, 15(1), 40-47.

Szeto, W. Y., Yang, L., Wong, R. C. P., Li, Y. C., \& Wong, S. (2017). "Spatio-Temporal Travel Characteristics of the Elderly in an Ageing Society". Travel Behaviour and Society, 9, 10-20.

Tang, L., Zhao, Y., Yin, K., \& Zhao, J. (2013). "Xiamen". Cities, 31, 615-624.

Tse, R. Y., \& Love, P. E. (2000). "Measuring Residential Property Values in Hong Kong". Property Management, 18(5), 366-374.

Wang, W., Yang, H., Sun, J., \& Gu, W. (2014). "A Study on the Spatial and Temporal Effects between School District and the Value of Residential Based on Hedonic Model". Statistics \& Information Forum, 29(9), 72-78.

Wang, X., Ge, Y., \& Zhang, H. (2010). "The Impacting Mechanism of Housing Prices in in the Older Sections of Nanjing". CO-Operative Economy \& Science, (12), 10-13.

Wang, Z., Mei, L., \& Wang, L. (2014). "Research on the Capitalization and Countermeasures to Equilibrium Distribution of Basic Educational Resources: A Case Study of Tianjin". Journal of Tianjing University of Finance and Economics, (7), 92-102.

Wen, H., Xiao, Y., \& Zhang, L. (2017). "School District, Education Quality, and Housing Price: Evidence from a Natural Experiment in Hangzhou, China". Cities, 66, 72-80.

Wen, H., Zhang, Y., \& Zhang, L. (2014). "Do Educational Facilities Affect Housing Price? An Empirical Study in Hangzhou, China". Habitat International, 42, 155-163.

Wong, R. C. P., Szeto, W. Y., Yang, L., Li, Y. C., \& Wong, S. C. (2017). "Elderly Users' Level of Satisfaction with Public Transport Services in a High-Density and TransitOriented City". Journal of Transport \& Health, 7, 209-217. 
Wong, R. C. P., Szeto, W. Y., Yang, L., Li, Y. C., \& Wong, S. C. (2018). "Public Transport Policy Measures for Improving Elderly Mobility". Transport Policy, 63, 73-79.

Wu, Q., Cheng, J., Chen, G., Hammel, D. J., \& Wu, X. (2014). "Socio-Spatial Differentiation and Residential Segregation in the Chinese City Based on the 2000 Community-Level Census Data: A Case Study of the Inner City of Nanjing". Cities, 39, 109-119.

Wu, Q., Edensor, T., \& Cheng, J. (2017). "Beyond Space: Spatial (Re) Production and Middle Class Remaking Driven by Jiaoyufication in Nanjing City, China". International Journal of Urban and Regional Research, (in press).

Wu, Q., Zhang, X., \& Waley, P. (2016). "Jiaoyufication: When Gentrification Goes to School in the Chinese Inner City". Urban Studies, 53(16), 3510-3526.

Wu, Q., Zhang, X., \& Waley, P. (2017). "When Neil Smith Met Pierre Bourdieu in Nanjing, China: Bringing Cultural Capital into Rent Gap Theory". Housing Studies, 32(5), 659-677.

Wu, X. (2006). "Difficulties and Countermeasures: Education Investment by Purchasing Housing". Gansu Social Sciences, (4), 121-123.

Xiamen Statistics Bureau. (2014). Xiamen Statistical Yearbook. Xiamen.

Xiamen Statistics Bureau. (2017). Xiamen Statistical Yearbook. Xiamen.

Yang, L. (2016). "The Mobility of the Elderly in Hong Kong: Policy Implications". (MPhil Thesis), University of Hong Kong, Pokfulam, Hong Kong SAR.

Yang, L. (2018). "Estimating the Walking Accessibility Premiums". Proceedings of 21st International Conference on Advancement of Construction Management and Real Estate, Singapore.

Yang, L., Chang, Y., Ma, Q., \& Gong, Q. (2015). "The Impact of Public Services on Housing Prices: A Case Study of Xiamen Island, China". Urban and Rural Planning, (2), 32-41.

Yang, L., \& Hong, S. (2013). "The Causes and Countermeasures of High Housing Prices in China from the Perspective of Supply and Demand". Fujian Architecture \& Construction, (12), 112-115.

Yang, L., Zhang, X., Hong, S., Lin, H., \& Cheng, G. (2016). "The Impact of Walking Accessibility to Public Services on Housing Prices: Based on the Cumulative Opportunity Measure". South China Journal of Economics, 34(1), 57-70.

Zhao, Y. (2003). "The Reform of Household Registration System in the Process of Economic Transformation". Urban Planning Reform, (1), 16-20. 